\title{
Targeted micronutrition for allergic patients - possible applications of a food for special medical purposes
}

\author{
Christoph Bergmann · Rainer Ehmann - Galateja Jordakieva · Hans-Joerg Koehler · Dirk Straub · \\ Eva Untersmayr · Ralph Dollner · Annette Sperl
}

Received: 1 February 2021 / Accepted: 3 March 2021 / Published online: 19 May 2021

(C) The Author(s) 2021, corrected publication 2021

\begin{abstract}
Summary A novel and recently launched food for special medical purposes was discussed by a multidisciplinary expert panel as an option for allergic patients. The newly developed lozenge contains the whey protein beta-lactoglobulin (BLG) as well as the micronutrients iron, zinc and vitamin A. BLG loaded with ligands (holo-BLG) is discussed as one factor of the allergy-protective farm effect in numerous scientific studies. Further studies reveal that holo-BLG shuttles its ligands specifically to immune cells, where it balances the specific nutrient demand and can thus lead to immune resilience. Based on the scientific background, the experts see a broad range of possible
\end{abstract}

PD Dr. med. C. Bergmann ( $\triangle)$

HNO im RKM740 interdisziplinäre Facharztklinik, Pariser

Straße 83-89, 40549 Düsseldorf, Germany

christoph.bergmann@rkm740-klinik.de

R. Ehmann

Ambulante Pneumologie mit Allergiezentrum, Stuttgart, Germany

G. Jordakieva

Universitätsklinik für Physikalische Medizin, Rehabilitation und Arbeitsmedizin, Medizinische Universität Wien, Vienna, Austria

H.-J. Koehler · D. Straub

Akademische Lehrpraxis, Universität Duisburg/Essen,

Essen, Germany

\section{E. Untersmayr}

Institut für Pathophysiologie und Allergieforschung, Medizinische Universität Wien, Vienna, Austria

R. Dollner

Lysaker Spesialistklinikk, Lysaker, Norway

HNO-Universitätsklinik, Mannheim, Germany

\section{A. Sperl}

Zentrum für Rhinologie und Allergologie, Wiesbaden, Germany applications for holo-BLG in the form of a lozenge, for example in patients suffering from multiple allergies, with sensitisation to rare allergens (including occupational allergens), tree pollen-associated food allergies or in general difficult treatment situations (e.g. allergies to animal dander or refusal of allergen immunotherapy). The expert panel describes the holoBLG lozenge as an innovative and additional option for allergic patients.

Keywords Beta-lactoglobulin - Farm effect . Lipocalin · Allergic rhinoconjunctivitis · Allergy

\section{Abbreviations}

AIT

apo-BLG

ARC

BLG

FSMP

holo-BLG

LCN-2

OTC

Allergen-specific immunotherapy
Unloaded beta-lactoglobulin
Allergic rhinoconjunctivitis
Beta-lactoglobulin
Food for special medical purposes
beta-lactoglobulin loaded with
ligands
Lipocalin-2
Over-the-counter

\section{Background}

In the context of the market launch of a novel food for special medical purposes (FSMP), applicable for the special dietary management of allergy patients, Bencard Allergie GmbH invited medical doctors specialised in allergy from Austria and Germany to a multidisciplinary expert discussion. Physicians specialised in paediatrics, ENT, pulmonology, clinical immunology, dermatology and occupational medicine were represented. The aim of this expert panel meeting, which was conducted as a video conference, was to have an open discussion on possible areas of application of the food for special medical purposes 
based on the published scientific evidence. At the beginning of the meeting, the inventor, Prof. Erika Jensen-Jarolim from Vienna, gave a summarising scientific introduction, followed by Prof. Karl-Christian Bergmann (Charité \& ECARF Institute, Berlin) presenting current clinical study data. The discussion was chaired by Dr. Sonja Guethoff (Bencard Allergie $\mathrm{GmbH}$, Munich). This publication summarises the contents of the expert panel meeting.

\section{Introduction}

The prevalence of atopic diseases is constantly increasing worldwide [1]. About one third of the population in Europe is affected by allergic rhinoconjunctivitis (ARC) [1]. The current guideline-based recommendations for the standard therapy of ARC [2, 3] essentially include oral $\mathrm{H} 1$ antihistamines, nasal glucocorticoids, nasal $\mathrm{H} 1$ antihistamine/glucocorticoids as a combination therapy and allergen-specific immunotherapy (AIT). AIT has a special role as it represents the only causal therapeutic option for the treatment of ARC to date [2, 3].

However, ARC is often still treated insufficiently [1, 2]. Therefore, there is a high demand for substances, which support the actual therapy such as food supplements or foods for special medical purposes (FSMP), which are available without prescription as over-thecounter (OTC) products. As the current notification procedure for registering food supplements and FSMP on the market does not require documentation of efficacy $[4,5]$, evidence-based food supplements or FSMP are a rare exception on the OTC market $[6,7]$.

The recently launched product was registered as a food for special medical purposes for the dietary management of allergic rhinitis and is available in pharmacies in Austria and Germany as an OTC product since the beginning of 2021.

\section{The protective farm effect as the basis for developing a lozenge}

Epidemiological studies have described the influence of environmental and nutritional factors on the development of allergic diseases and their symptom burden for many years. A prominent example of this is the socalled "farm effect". This term describes the allergyprotective effect, which is characterised both by the general living conditions on farms with dairy farming and by the protective effects of the consumption of raw milk $[8,9]$. The latter effect, however, is limited to unprocessed milk only and cannot be demonstrated for consumption of commercially available cow's milk. One explanation is the industrial milk processing step, which leads to denaturation of potentially immunemodulating proteins [10]. This also affects bovine beta-lactoglobulin (BLG), representing more than $50 \%$ of whey protein. BLG belongs to the protein family of lipocalins and acts as a transport protein for micronu- trients [11]. It was recently demonstrated that BLG, associated with zinc, is also detectable in stable dust, in the mattress dust of the families living on farms with dairy farming and, depending on distance, in the surrounding air of cattle stables. In these instances, BLG is dispersed via aerosols and can be detected in the area around the stable [12]. Further studies proved that BLG associated with zinc reduces T-cell proliferation in vitro and induces an allergy-protective Th1 milieu [12].

\section{Holo-BLG - targeted micronutrition of immune cells leads to immune resilience}

The immune-modulating effect of BLG is based on targeted micronutrition of immune cells, whereby the loading state of the bovine BLG plays a central role $[11,13,14]$. If BLG is loaded with micronutrients, this is referred to as holo-BLG. The micronutrients iron, zinc and vitamin A in the holo-BLG lozenge are bound as ligands in the central binding pocket of the BLG molecule and thus contribute to the overall effect. The micronutrient iron seems to play a central role here, which can be attributed to two pathophysiological aspects of atopic diseases. On the one hand, there is an epidemiological and experimental correlation between functional iron deficiency and atopy or allergy [15]. On the other hand, reduced levels of human lipocalin-2 (LCN-2) have been described in allergic patients [16]. LCN-2 is a transport protein and, among other things, fulfils the function to transport complexed iron $\left(\mathrm{Fe}^{3+}\right)$ specifically to critical cell populations such as immune cells [17]. The combination of these two pathophysiological conditions results in a functional iron deficiency in allergic patients, meaning the body's own depot of iron is limited for cellular functions. An intracellular iron deficiency causes an increased degranulation of mast cells and the promotion of a Th2 milieu as a decisive immunological switch in atopic diseases [17].

Compensation of this functional iron deficiency is achieved by BLG loaded with iron-polyphenol complexes: In mouse studies, the comparison of holo-BLG with the unloaded form (apo-BLG) showed that holoBLG leads to an improved iron status of the immune cells. In addition, when treated with holo-BLG, a reduced antigen presentation was observed by masking B- and T-cell epitopes. Furthermore, supplementation with holo-BLG reduced IgE binding and mast cell degranulation in the effector phase [11]. The additional loading of BLG with vitamin A and zinc [12, 13] could further support the immune-modulating effects and was incorporated into the development of the holo-BLG lozenge.

In addition to in vitro experiments and mouse models $[11,18]$, the efficacy of holo-BLG in allergic patients has so far been investigated in two clinical pilot trials. In a first randomised, double-blind, placebo-controlled trial, a total of 20 female patients 
with birch pollen allergy were enrolled and received holo-BLG or placebo daily for 6 months (including the birch pollen season). In the holo-BLG group, the daily symptom load during the birch pollen season was significantly lower than in the placebo group. Furthermore, immune cells of the patients supplemented with holo-BLG had higher intracellular iron compared to placebo [19]. These promising results are currently being investigated in a larger cohort.

Another proof-of-concept study investigated the effect of holo-BLG in patients with house dust mite allergy in a standardised and validated allergen exposure chamber. Supplementation with holoBLG achieved a significant improvement of $60 \%$ $(p=0.0034)$ in the primary endpoint (total nasal symptom score) [20].

Overall, both studies demonstrated an excellent tolerability of the holo-BLG lozenge.

In summary, the available study results $[19,20]$ and the associated immunological effects [11] indicate that supplementation with holo-BLG can lead to immune resilience in patients with allergic rhinitis, whereby this phenomenon is not allergen-specific. The preclinical data could now be supported accordingly by early clinical data. Further clinical studies are being planned.

\section{In which situations could holo-BLG be recommended?}

Overall, the causal treatment of allergic patients with AIT remains undisputed. However, the expert panel agreed that the holo-BLG lozenge generally represents an innovative option for many patients with type I allergies due to its allergen-unspecific, immune-modulating mode of action. The application is considered in a variety of clinical scenarios.

Due to the allergen-unspecific mode of action of holo-BLG, its use in patients with multiple allergies was discussed. It is often not possible to achieve satisfactory symptom control despite guideline-compliant causal (AIT) and drug therapy in this specific patient group, so that holo-BLG could be a supportive option.

This also applies to patients with allergies to rare allergens, where no suitable AIT preparations are available. In this context, the use of holo-BLG in occupational allergies (as tertiary prevention), or possibly already in secondary prevention of sensitisation to occupational allergens in allergic or atopic patients was highlighted as a conceivable possibility.

Patients with tree pollen-associated food allergies (oral allergy syndrome) are not often treated efficiently with available therapies. For patients who suffer a lot and claim limited quality of life, it seems possible to apply holo-BLG as a supportive product.

The use of the holo-BLG lozenge was also discussed as an option in the context of difficult treatment situations in everyday practice. An important group are patients allergic to animal dander who want to keep their pet.

In addition, situations arising due to the presence of a contraindication or rejection of clinically indicated AIT were mentioned. For these patient groups, the optional use of holo-BLG was endorsed by the expert panel.

The application of holo-BLG has been primarily discussed for adolescents and adults. The use of the holo-BLG lozenge is possible from the age of three years, given that the child can reliably suck a lozenge without swallowing it.

Regarding the application in children, sufficient clinical data for a final conclusive evaluation is pending. However, an observational study of the application is currently being conducted in four sites in Germany. Clinical effects and tolerability of the holoBLG lozenge in adults, but also in children and adolescents will be documented.

The extension of clinical studies across subject demographics and its mode of action is desirable, especially given the fact of a potential allergy-preventive application of holo-BLG.

Limitations for the use are based on the composition of the lozenge. Supplementation is contraindicated in the presence of a confirmed milk protein allergy. In addition, according to the expert panel, they would prefer that patients inform their treating physician about the intake of holo-BLG.

\section{Conclusion}

The expert panel rates the supplementation of the lozenge, with holo-BLG, as an important innovation that could enable the farm effect and thus might represent a new and additional option for allergic patients. Based on the published evidence, holo-BLG might represent a supportive approach for allergic patients.

Conflict of interest The expert discussion was organised and financed by Bencard Allergie GmbH. All authors received a consultancy fee. R. Dollner additionally acted as medical writer and received a fee for this. C. Bergmann and A. Sperl received fees from Bencard for research activities and lectures. R. Ehmann, H.J. Koehler, D. Straub and A. Sperl are study physicians in studies sponsored by Bencard. G. Jordakieva and E. Untersmayr declare that they have no other competing interests.

Open Access This article is licensed under a Creative Commons Attribution 4.0 International License, which permits use, sharing, adaptation, distribution and reproduction in any medium or format, as long as you give appropriate credit to the original author(s) and the source, provide a link to the Creative Commons licence, and indicate if changes were made. The images or other third party material in this article are included in the article's Creative Commons licence, unless indicated otherwise in a credit line to the material. If material is not included in the article's Creative Commons licence and your intended use is not permitted by statutory regulation or 
exceeds the permitted use, you will need to obtain permission directly from the copyright holder. To view a copy of this licence, visit http://creativecommons.org/licenses/by/4.0/.

\section{References}

1. Agache I, Akdis CA, Chivato T, Hellings P, Hoffman-Sommergruber K, Jutel M, et al. EAACI White Paper on Research, Innovation and Quality Care. EAACI. 2018.

2. Bousquet J, Schunemann HJ, Togias A, Bachert C, Erhola M, Hellings PW, et al. Next-generation Allergic Rhinitis and Its Impact on Asthma (ARIA) guidelines for allergic rhinitis basedon Grading ofRecommendations Assessment, Development and Evaluation (GRADE) and real-world evidence. JAllergy Clin Immunol. 2020;145:70-80:e3.

3. Roberts G, Pfaar O, Akdis CA, Ansotegui IJ, Durham SR, Gerth van Wijk R, et al. EAACI Guidelines on Allergen Immunotherapy: Allergic rhinoconjunctivitis. Allergy. 2018;73:765-98.

4. Nahrungsergänzungsmittelverordnung vom 24. Mai 2004 (BGBl. IS. 1011), die zuletzt durch Artikel 11 der Verordnung vom 5. Juli 2017 (BGBl. IS. 2272) geändert worden ist; (2004)

5. DelegierteVerordnung (EU) 2016/128 der Kommissionvom 25. September 2015 zur Ergänzung der Verordnung (EU) Nr. 609/2013 des Europäischen Parlaments und des Rates im Hinblick auf die besonderen Zusammensetzungs- und Informationsanforderungen für Lebensmittel für besondere medizinischeZwecke; (2016)

6. Kramer MF, Heath MD. Probiotics in the treatment of chronic rhinoconjunctivitis and chronic rhinosinusitis. JAllergy (cairo). 2014;2014:983635.

7. Bergmann K-C, Krause L, Hiller J, Becker S, Kugler S, Tapparo M, et al. First evaluation of a symbiotic food supplement in an allergen exposure chamber in birch pollen allergic patients. World Allergy Organ J. 2020;14:100494.

8. Loss G,ApprichS, WaserM, KneifelW, GenuneitJ,BucheleG, et al. The protective effect of farm milk consumption on childhood asthma and atopy: the GABRIELA study. JAllergy Clin Immunol. 2011;128:766-73.e4.

9. Lluis A, Depner M, Gaugler B, Saas P, Casaca VI, Raedler D, et al. Increased regulatory $\mathrm{T}$-cell numbers are associated with farm milk exposure and lower atopic sensitization and asthma in childhood. J Allergy Clin Immunol. 2014;133:551-9.

10. Abbring S, Hols G, Garssen J, van Esch B. Raw cow's milk consumption and allergic diseases-The potential role of bioactive whey proteins. Eur J Pharmacol. 2019;843:55-65.
11. Roth-Walter F, Afify SM, Pacios LF, Blokhuis BR, Redegeld F, Regner A, et al. Cow's milk protein beta-lactoglobulin confers resilience against allergy by targeting complexed iron into immune cells. J Allergy Clin Immunol. 2021;147(e4):321-34.

12. Pali-Schöll I, Bianchini R, Hofstetter G, Winkler S, Ahlers S, Altemeier T, et al. Bauernhofeffekt anders gedacht: bovines Beta-Laktoglobulin kommt zusammen mit seinen Liganden im Stallstaub vor und zeigt in vitro einen Allergieprotektiven Effekt. Allergo J Int. 2020;29:201-2.

13. Hufnagl K, Ghosh D, Wagner S, Fiocchi A, Dahdah L, Bianchini R, etal. Retinoic acid preventsimmunogenicity ofmilk lipocalin Bos $\mathrm{d} 5$ through binding to its immunodominant T-cell epitope. Sci Rep. 2018;8:1598.

14. Jensen-Jarolim E, Roth-Walter F, Jordakieva G, Pali-Schöll I. Allergens and Adjuvants in Allergen Immunotherapy for Immune Activation, Tolerance, and Resilience. J Allergy Clin Immunol Pract. 2021; https://doi.org/10.1016/j.jaip. 2020.12.008.

15. Roth-Walter F, Pacios LF, Bianchini R, Jensen-Jarolim E. Linking iron-deficiency with allergy: role of molecular allergens and the microbiome. Metallomics. 2017;9:1676-92.

16. Roth-Walter F, Schmutz R, Mothes-Luksch N, Lemell P, Zieglmayer P, Zieglmayer R, et al. Clinical efficacy of sublingual immunotherapy is associated with restoration of steady-state serum lipocalin 2 after SLIT: a pilot study. World Allergy Organ J. 2018;11:21.

17. Jensen-Jarolim E, Pacios LF, Bianchini R, Hofstetter G, RothWalter F. Structural similarities of human and mammalian lipocalins, and their function in innate immunity and allergy. Allergy. 2016;71:286-94.

18. Afify SM, Pali-Schöll I, Hufnagl K, Hofstetter G, El-Bassuoni M, Roth-Walter F, et al. Bovine Holo-beta-Lactoglobulin cross-protects against pollen allergies in an innate manner in BALB/c mice: potential model for the farm effect. Front Immunol. 2021; https://doi.org/10.3389/ fimmu.2021.611474.

19. BartosikT, Afify SM, Petje L-M, Bastl M, Berger U, Hufnagl K, et al. Neue Immuntablette vermindert in einer doppelblind, placebo-kontrollierten Studie die Symptomlast bei Allergikerinnen während der Birkenpollensaison über natürlicheImmunmechanismen. AllergoJInt. 2020;29:223.

20. Bergmann K-C, Graessel A, Raab J, Banghard W, Krause L, Becker S, et al. Targeted micronutrition via holo-BLG based on the farm effect in house dust mite allergic rhinoconjunctivitis patients-first evaluation in a standardized allergen exposure chamber. Allergo J Int. 2021; https://doi.org/10. 1007/s40629-021-00163-9. 